\title{
Process characterization of wet etching for high aspect ratio microneedles development
}

\author{
NORAZREEN Abd Aziz, ${ }^{1 a}$ MUHAMAD Ramdzan Buyong ${ }^{2 b}$ and \\ Burhanuddin Yeop Majlis ${ }^{3 c}$
}

\author{
${ }^{1,2,3}$ Institute of Microengineering and Nanoelectronic (IMEN), \\ Universiti Kebangsaan Malaysia \\ 43600, Bangi, Selangor, Malaysia \\ aazreen@ vlsi.eng.ukm.my, ${ }^{b}$ ramdzan.buyong@mimos.my cburhan@vlsi.eng.ukm.my
}

Keywords: Microneedles, wet isotropic etch, HNA

\begin{abstract}
Research on microneedles has been increasing rapidly as to overcome the drawbacks of conventional needle which can results in painful during injection, tissue damage and skin infection at the injected site. This paper presents characterization process of wet isotropic etch for solid microneedles array development. This approach utilizes HNA etchant to build the outer shape of solid microneedles. Works has been carried out to investigate the isotropic etching behavior of HNA in different temperature ranging from 20 to 50 degrees, various agitation rate ranging from $0 \mathrm{rpm}$ to $450 \mathrm{rpm}$ and on the various window size ranging from $100 \mu \mathrm{m}$ to $500 \mu \mathrm{m}$. Characterization on those factor, determine the effect of vertical and lateral etch rate variations, surface quality and the geometry obtained. The experimental responses of vertical etch rate, lateral etch rate and high aspect ratio reported. The obtained etching properties will be applied to develop recipes to fabricate outer shape of solid microneedles' tip.
\end{abstract}

\section{Introduction}

Delivering medicine through skin is seen as a desirable alternative instead of taking it orally. Patients tend to forget to take their medications and tired to swallow the pills especially if they have to take it several times in a day. Transdermal drug delivery which is a form of controlled delivery promises a convenient administration of drugs over extended period of time, reducing the side effects and provides a constant dosage. This alternative approach is utilizing solid microneedles array which are effective in forming micropores; large enough for molecules to enter in the outer skin layer. The size of disruptions generated by each of these methods is believed to be of nanometer dimensions, which is large enough to permit transport of small drugs and, in some cases, macromolecules, but not large enough to cause any damage of any clinical significance[1].

Human pain studies have shown that insertion of microneedles can be painless and free from skin irritation. In contrast, conventional needles not only need an expert to perform the injection but also can cause injection to be painful due to larger needle size and deeper penetration. McAllister et al [2] demonstrated in vitro experiments showed that inserting microneedles into a skin can increase its permeability for small drugs, large 
molecules and nanoparticles by orders of magnitude. Sharp-tipped and high aspect ratio needle is a requirement issue, as it can lead to easy penetration and less force for insertion. To get a large volume of drugs to be delivered into the skin, the microneedle must be arranged in array. It creates multiple micro pores on the skin. In this study, the shape of the needle tip is developed using wet isotropic etching technology which HNA was utilized as the etchant. Isotropic behavior; etch in all crystallographic directions at the same rate. Thus, resulting in a smooth underetch semi-rounded profile. In this behavior, it seems that the meeting point of two underetching semi-rounded profile will produce the outer needle shape with sharp tip.

Previously, we work on the characterization of HNA composition that involved the usage of $\mathrm{HF}, \mathrm{HNO}_{3}$ with $\mathrm{H}_{2} \mathrm{O}$ or $\mathrm{CH}_{3} \mathrm{COOH}$ as diluents [3]. It is observed that microneedles with a smooth etched surface can be obtained using HNA solution with 60 to $70 \mathrm{wt} \% \mathrm{HNO}_{3}$. In this paper we are focusing on the investigation of the isotropic etching behavior in optimum HNA etchant under different condition. We will study the behavior of silicon in HNA composition (20\%wt $\mathrm{HF}: 70 \%$ wt $\mathrm{HNO}_{3}: 10 \%$ wtCH${ }_{3} \mathrm{COOH}$ ) in various temperature ranging from 20 to 50 degrees, in various agitation rate ranging from $0 \mathrm{rpm}$ to $450 \mathrm{rpm}$ and on the various window size ranging from $100 \mu \mathrm{m}$ to $500 \mu \mathrm{m}$. Characterization on those factor, determine the effect of vertical and lateral etch rate variations, surface quality and the geometry obtained. Investigation is carried out only for circular mask.

\section{Characterization Procedure}

Figure 1 shows the schematic of process flow of characterization procedure using the circular mask shape. A standard (100) silicon wafer, 600um thick with 200nm deposited silicon nitride (LPCVD) over the substrate is used as a starting material. A photoresist layer (AZ1500 $2000 \mathrm{rpm}$ ) is coated onto the nitride layer. Then, samples are exposed by using mask aligner and hard bake at $120^{\circ} \mathrm{C}$ for 5 minutes. The exposed photoresist is removed by soaking the wafer in liquid developer, AZ300MIF leaving the desired circular array of photoresist on the nitride layer. The wafer is immersed into 6:1 BHF (Buffered Hydroflouric) that etched the uncovered nitride pattern. The present photoresist is then removed by soaking the wafer into acetone which left the circular array of nitride as a mask for the next step. The wafer is then cut into 15 pieces, each five of will be used in three different characterization processes (temperature, agitation rate and window size). Characterization of window size involved five samples with an array of $200 \mu \mathrm{m}$ silicon nitride circular mask in size. Each of them has different opening window size i.e $100 \mu \mathrm{m}, 200 \mu \mathrm{m}, 300 \mu \mathrm{m}, 400 \mu \mathrm{m}$ and $500 \mu \mathrm{m}$ in size. While characterization of temperature used five samples with an array of $200 \mu \mathrm{m}$ silicon nitride circular mask in size and an opening window size of $100 \mu \mathrm{m}$. All five samples were etched in the HNA solution under five different temperatures i.e $20^{\circ} \mathrm{C}, 30^{\circ} \mathrm{C}, 35^{\circ} \mathrm{C}, 40{ }^{\circ} \mathrm{C}$ and $50{ }^{\circ} \mathrm{C}$. For HNA agitation rate characterization, another five samples with an array of $200 \mu \mathrm{m}$ with an array of $200 \mu \mathrm{m}$ silicon nitride circular mask in size were used. All five samples were etched in the HNA solution under five different agitation rate i.e 0rpm, 350rpm, 367rpm, 400rpm and 450rpm. All three characterization process used the optimum HNA composition i.e $\mathrm{HF}: \mathrm{HNO}_{3}: \mathrm{CH}_{3} \mathrm{COOH} ; 2: 7: 1$ [4] solution for 3 minutes. The samples were observed under SEM for the lateral etching and vertical etching profile. 


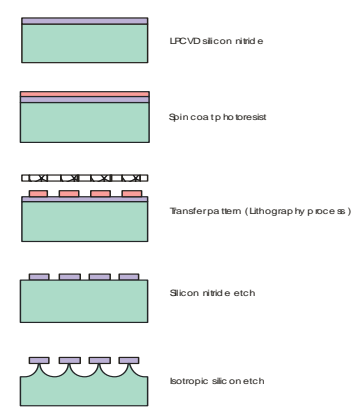

Fig 1 Process flow for the characterization of isotropic

\section{Result and Discussion}

Vertical and lateral etch rate of window size characterization are plotted in the graph as shown in Figure 2. From the graph, it is seen that both lateral and vertical etch rate is increased proportionally with the increasing opening window size. It is observed that window size at $300 \mu \mathrm{m}, 400 \mu \mathrm{m}$ and $500 \mu \mathrm{m}$ will produce a microneedles with high aspect ratio structure since the ratio of vertical over lateral etch rate is more than 1 . It is also observed that the resulting etched surface is smooth as shown in Figure 3. For HNA temperature characterization, vertical and lateral etch rate were plotted in the graph as shown in Figure 4. It is seen that HNA solution with temperature below $30^{\circ} \mathrm{C}$ produced an identical vertical and lateral etch rate. Meanwhile HNA solution that heated above 35 ${ }^{\circ} \mathrm{C}$ will produce a structure with high aspect ratio less than 1 as the lateral etch rate is higher than the vertical etch rate. It is also observed that temperature above $35^{\circ} \mathrm{C}$ gives a rough quality etched surface as shown in Figure 5. Vertical and lateral etch rate of agitation rate characterization are plotted in the graph as shown in Figure 6. It is observed that both vertical and lateral etch rate increased proportionally with the agitation rate. From the graph, it can be concluded that agitated HNA solution will produce an isotropic structure with high aspect ratio. Agitated solution also produced a smooth etched surface as shown in Figure 7.

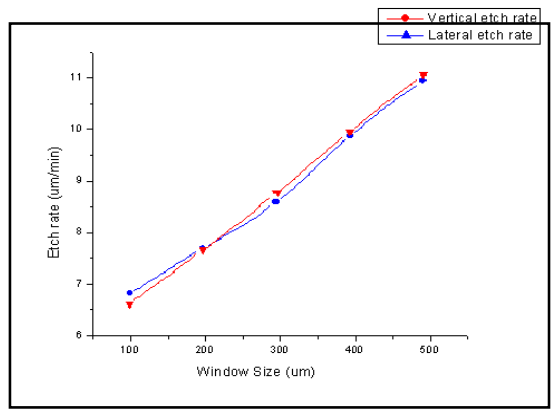

Figure 2 Etch rates at various point of window size

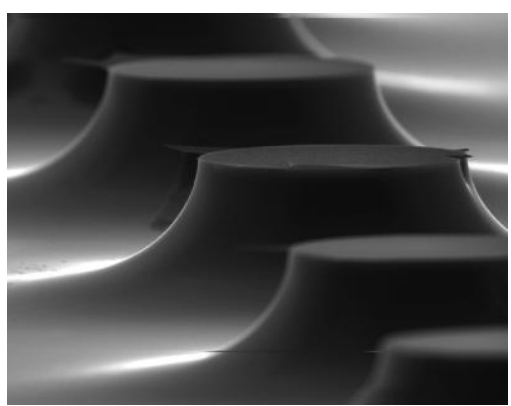

Figure 3 SEM micrograph of etched structure using $300 \mu \mathrm{m}$ window size 


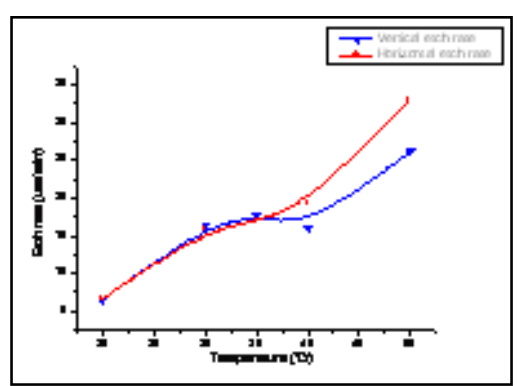

Figure 4 Etch rates at various point of temperature

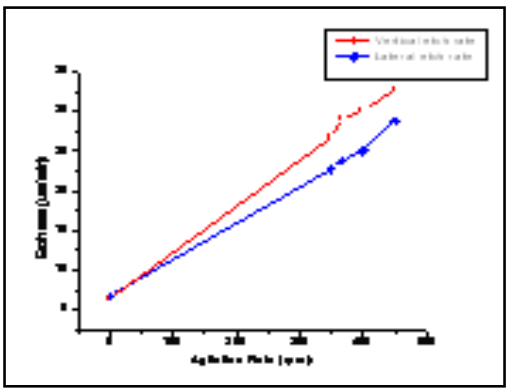

Figure 6 Etch rates at various point of agitation rate

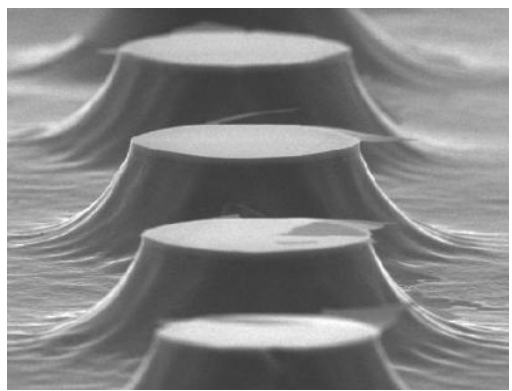

Figure 5 SEM micrograph of etched structure using HNA solution at $35^{\circ} \mathrm{C}$

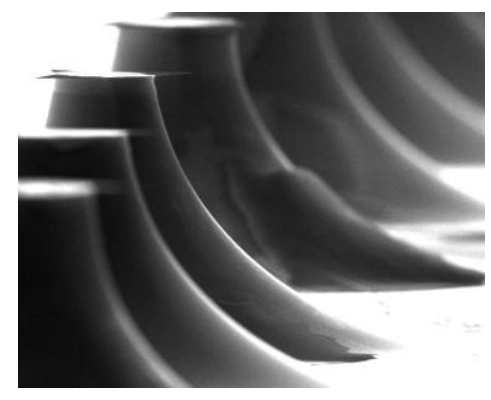

Figure 7 SEM micrograph of etched structure using HNA solution agitated at 350rpm

\section{Conclusion}

In this paper, process characterization of isotropic wet etching under three conditions i.e opening window size, etchant temperature and etchant agitation rate is discussed. Factor that contributes to the development of high aspect ratio microneedles has been identified. Agitation rate is the main factor that contributes to the high aspect ratio structure development followed by the opening window size. These two factor also produced a smooth surface quality structure. Heating up the HNA solution will make the etched surface structure become rough and non uniform.

\section{References}

[1]B. Stoeber and D. Liepmann, Arrays of Hollow Out-of-Plane Microneedles for Drug Delivery, Journal of Microelectromechanical Systems. Vol. 14, no. 3, pp. 472-479 (2005).

[2] J. Ji, F. E. H. Tay, J. Miao and C. Iliescu, Microfabricated microneedles with porous tip for drug delivery, Journal of Micromechanics and Microengineering Vol. 16, pp. 958-964 (2006).

[3]H. Robbins and B. Schwartz. Chemical Etching of Silicon-II: The System $\mathrm{HF}, \mathrm{HNO}_{3}, \mathrm{H}_{2} \mathrm{O}$ and $\mathrm{HC}_{2} \mathrm{C}_{3} \mathrm{O}_{2}$, Journal of Electrochemical Soc. Vol. 107, pp. 108-11 (1960).

[4] Aziz, N.A., Bais, B., Hamzah, A.A and Majlis, B.Y. Characterization of HNA etchant for silicon microneedles array. IEEE International Conference on Semiconductor Electronics, ICSE (2008) pp.203-206 